\title{
Penggunaan Prezi untuk Media Pembelajaran Matematika Materi Fungsi
}

\author{
Rohiman1 , Bambang Sri Anggoro' \\ ${ }^{1}$ Universitas Islam Negeri Raden Intan Lampung. Jalan Endro Suratmin, Sukarame, Bandar \\ Lampung 35133, Indonesia. \\ E-mail: rohimancan@yahoo.com
}

\begin{abstract}
Abstrak
Penelitian ini bertujuan mengembangkan media pembelajaran matematika berbasis prezi untuk meningkatkan minat belajar pada materi fungsi. Media yang dikembangkan adalah media pembelajaran matematika menggunakan software Prezi. Jenis penelitian adalah penelitian dan pengembangan (Research and Development) dengan menggunakan model penelitian dan pengembangan yang sudah diadaptasi meliputi tahap-tahap: (1) Analisis; (2) Desain; (3) Pengembangan; (4) Uji Coba(Implementasi). Subjek uji coba penelitian ini berjumlah 33 peserta didik kelas VIII dengan materi fungsi. Pada penelitian pengembangan ini dengan tujuan utama sebagai pengembangan produk dan pengujian keefektifan produk dalam mencapai tujuan dalam penelitian. Instrumen pengumpulan data yang digunakan adalah angket validasi media, angket validasi materi, dan angket respon peserta didik. Hasil utama penelitian ini adalah media pembelajaran matematika menggunakan software Prezi. Kualitas media pembelajaran matematika menggunakan software Prezi adalah sangat baik berdasarkan hasil validasi ahli media dengan skor $93 \%$ dan berdasarkan ahli materi adalah baik dengan skor $77,5 \%$, dan respon peserta didik terhadap media pembelajaran adalah sangat baik dengan skor 83,9\% dengan menggunakan skala Likert.
\end{abstract}

Kata kunci: Pengembangan, Media Pembelajaran, Aplikasi Prezi, Minat Belajar, Fungsi

\begin{abstract}
This study aims to develop prezi-based mathematics learning media to increase interest in learning in the function material. The media developed is a mathematics learning media using Prezi software. This type of research is research and development (Research and Development) using an adapted research and development model which includes stages: (1) Analysis; (2) Design; (3) Development; (4) Trial (Implementation). The subjects of this research trial were 33 eighth grade students with function material. In this development research with the main objectives as product development and testing the effectiveness of the product in achieving the objectives in the study. Data collection instruments used were media validation questionnaire, material validation questionnaire, and student response questionnaire. The main result of this research is mathematics learning media using Prezi software. The quality of mathematics learning media using Prezi software is very good based on the results of media expert validation with a score of $93 \%$ and based on material experts is good with a score of $77.5 \%$, and the response of students to learning media is very good with a score of $83.9 \%$ using a scale Likert.
\end{abstract}

Keywords: Development, Learning Media, Prezi Application, Interest in Learning, Function

\section{PENDAHULUAN}

Kemajuan ilmu pengetahuan dan teknologi menciptakan proses pembelajaran yang menarik tidaklah sulit dilakukan. Pendidikan berbasis Teknologi Informasi dan Komunikasi
(TIK) merupakan sarana interaksi yang dapat dimanfaatkan oleh pendidik, tenaga kependidikan, dan peserta didik dalam meningkatkan efektifitas, kualitas, produktifitas serta akses pendidikan. Perkembangan pendidikan 
Desimal, 2 (1), 2019 - 24

Rohiman, Bambang Sri Anggoro

berbasis Teknologi Komunikasi dan Informasi (TIK) di Indonesia masih belum di optimal dibandingkan dengan negara-negara lain, jika dibandingkan negara tetangga seperti Singapura dan Malaysia, negara kita masih jauh tertinggal (Sutopo, 2012).

Di era perkembangan IPTEK saat ini banyak sekali jenis media pembelajaran yang dapat digunakan, diantaranya media pembelajaran multimedia yang melibatkan beberapa jenis media dan peralatan secara terintegrasi dalam suatu proses atau kegiatan pembelajaran. Salah satu media pembelajaran multimedia adalah menggunakan software Prezi (Sujarwo \& Kholis, 2016).

Prezi adalah sebuah perangkat lunak yang digunakan untuk membuat presentasi (Restika, Ibrahim, \& Kuswanti, 2016). Selain untuk presentasi, prezi juga dapat digunakan sebagai alat untuk mengeksplorasi dan berbagi ide di atas kanvas virtual. Prezi menjadi unggul karena program ini menggunakan zooming user interface (ZUI), yang memungkinkan pengguna prezi untuk memperbesar dan memperkecil tampilan media presentasi mereka. Prezi digunakan sebagai alat untuk membuat presentasi dalam bentuk linier maupun non-linier (Rodhi \& Wasis, 2014), yaitu presentasi terstruktur sebagai contoh dari presentasi linier, atau presentasi berbentuk peta-pikiran (mind-map) sebagai contoh dari presentasi nonlinier (Rusyfian, 2016).

Berdasarkan penelitian terdahulu, telah dilakukan beberapa penelitian dalam mengembangkan media pembelajaran (Ali, 2009; Andreanto \& Suprianto, 2018; Jannah, Sugianto, \& Sarwi, 2012; Megawati, 2014; Nisa' \& Agung, 2014; Purwanti, 2015; M. Safitri, Hartono, \& Somakim, 2013; M. R. Safitri, Budiharti, \& Ekawati, 2014; Setyono, Sukarmini, \& Wahyuningsih, 2013;
Suprapti, 2016; Widiyatmoko, 2013; Yulianti, Buchori, \& Murtianto, 2017) untuk meningkatkan minat baca, minat kewirausahaan serta pemahaman (Khoiri, Hindarto, \& Sulhadi, 2011; Setyono et al., 2013; Wahyudin, Sutikno, \& Isa, 2010), meningkatkan hasil belajar (Antika \& Suprianto, 2016; Setiawan \& Joko, 2016; Somayasa, Natajaya, \& Candiasa, 2013; Wahyudi, Hariyadi, \& Hariani, 2014) dan meningkatkan kemampuan berpikir kritis peserta didik (Amir \& Wardana, 2017; Damayanti, Ngazizah, \& Setyadi K, 2013; I \& Mahayukti, 2013; Rodhi \& Wasis, 2014) serta penggunaan Sofware Prezi telah digunakan dalam beberapa penelitian terdahulu (Argarini \& Sulistyorini, 2018; Hartini, Misbah, Dewantara, Oktovian, \& Aisyah, 2017; Hidayati \& Santoso, 2016; Karim \& Agung, 2018; Restika et al., 2016; Retnawati, Rasiman, \& Handayani, 2018; Sujarwo \& Kholis, 2016; Surani \& Ampera, 2017; Utari, Kurniawan, \& Fatmaryanti, 2014) dan juga pengukuran minat belajar dalam suatu penelitian (Asfuriyah \& Nuswowati, 2015).

Penelitian terdahulu yang telah dipaparkan di atas memiliki persamaan dan perbedaan dalam penelitiannya. Persamaan dari penelitian tersebut yaitu sama-sama mengembangkan media pembelajaran dan mendapat respon yang baik oleh peserta didik. Sedangkan perbedaannya dari setiap penelitian tersebut terletak pada penggunaan software yang digunakan serta materi yang dibahas dalam media pembelajaran dari masing-masing penelitian. Namun dalam penelitian ini akan dilakukan keterbaharuan dari penelitian sebelumnya yaitu mengembangan media pembelajaran matematika berbasis prezi untuk meningkatkan minat belajar peserta didik pada pokok bahasan fungsi. 
Desimal, 2 (1), 2019 - 25

Rohiman, Bambang Sri Anggoro

\section{METODE}

Metode penelitian yang digunakan dalam penelitian ini adalah metode penelitian dan pengembangan atau $R \&$ $D$ (Research and Development). Penelitian (R\&D) juga dapat diartikan metode penelitian yang digunakan untuk menghasilkan produk tertentu , dan menguji keefektifan produk tersebut (Sugiyono, 2013). Subjek uji coba dalam penelitian ini adalah peserta didik kelas VIII di SMP/MTs. Penelitian ini akan menggunakan model penelitian dan pengembangan yang di adaptasi dari Munir. Prosedur tersebut terdiri dari lima tahap, yaitu analisis, desain, pengembangan, uji coba (implementasi), dan implementasi (Munir, 2012).

Teknik pengumpulan data yang digunakan dalam penelitian dan pengembangan ini menggunakan angket validasi materi, validasi media dan angket respon peserta didik terhadap media pembelajaran matematika. Cara penyampaian angket langsung dibagikan kepada ahli materi, ahli media sebelum produk di uji coba kepada peserta didik. Setelah selesai materi dan media divalidasi selanjutnya media pembelajaran matematika berbasis prezi untuk meningkatkan minat belajar peserta didik materi fungsi siap di uji coba ke lapangan agar kita mendapatkan respon peserta didik yang sangat menarik terhadap media pembelajaran matematika berbasis prezi dengan menggunakan angket respon peserta didik.

Analisis data pada penelitian ini adalah menggunakan teknik analisis deskriptif kualitatif dan kuantitatif . Kualitatif adalah data yang diperoleh berupa masukan dari validator pada tahap validasi, juga masukan dari ahli media, ahli materi dan peserta didik. Sedangkan kuantitaf adalah data yang memaparkan hasil pengembangan produk yang berupa media pembelajran matematika berbasis aplikasi prezi (zooming presentation) yang diperoleh dari pengisian lembar penilaian oleh para ahli dan respon peserta didik dimuat dalam bentuk Tabel 1 sebagai berikut :

Tabel 1. Kriteria Penilaian Validator Ahli

\begin{tabular}{lcl}
\hline No & Skala Nilai Tingkat Validasi & \multicolumn{1}{c}{ Tingkat Validasi } \\
1 & $81-100$ & Sangat Baik / Sangat Menarik \\
2 & $61-80$ & Baik / Menarik \\
3 & $41-60$ & Sedang / Cukup \\
4 & $21-40$ & Tidak Baik / Tidak Menarik \\
5 & $0-20$ & Sangat Tidak baik / Sangat Tidak Menarik \\
\hline
\end{tabular}

Setelah penilaian selesai dilakukan hasil penilaian dari skor kevalidan dihitung dan dikonversikan dalam criteria kelayakan media pembelajaran dapat dilihat pada rumus rata-rata, dimana:

Persentase jawaban dengan rumus skala likert (Sugiyono, 2013).

$$
\begin{aligned}
& x_{i}=\frac{\sum s}{S_{\max }} \times 100 \% \\
& \text { Keterangan : } \\
& x_{i}=\text { Nilai Kelayakan } \\
& \sum \mathrm{S}=\text { Jumlah skor }
\end{aligned}
$$

$$
S_{\max }=\text { Jumlah skor seluruh }
$$

\section{PEMBAHASAN}

Penelitian dan pengembangan ini untuk menghasilkan sebuah produk berupa media pembelajaran matematika berbasis prezi ini mengacu pada tahap penelitian dan pengembangan milik Munir (Munir, 2012) yang terdiri dari empat tahap, yaitu tahap analisis kebutuhan, tahap desain, tahap pengembangan, dan tahap uji coba. 
Desimal, 2 (1), 2019 - 26

Rohiman, Bambang Sri Anggoro

Proses pengembangan ini dimulai dari tahap analisis terhadap pengembangan produk yang dilakukan dua tahap yaitu studi lapangan dan studi literatur. Kegiatan studi lapangan dilakukan dalam bentuk observasi dan wawancara dengan guru pengampu matapelajaran matematika mengenai proses pembelajaran, sedangkan studi literatur dilakukan dalam bentuk mencari teori dan materi yang mendukung serta berkaitan dengan pengembangan media pembelajaran matematika berbasis aplikasi prezi. Setelah tahap analisis, kemudian dilanjutkan dengan tahap desain atau rancangan sebuah desain media.

Tahap desain meliputi beberapa tahap yaitu: pemilihan desain template merupakan tahap awal sebelum melakukan input data. Tahap input data dilakukan setelah melakukan edit materi terlebih dahulu dari berbagai sumber materi. Sumber materi yang dimaksud disini adalah buku,gambar, video, modul tentang materi fungsi, modul online yang memuat materi fungsi dan mengambil sumber dari beberapa blog di internet. Materi yang diperoleh kemudian dibuat ringkasan materi yang diurutkan sesuai dengan silabus dan rencana pelaksanaan pembelajaran (RPP) yang digunakan di SMP/MTs.
Tahap pengembangan merupakan proses penilaian yang dilakukan oleh ahli materi dan ahli media melalui proses validasi bertujuan untuk mengetahui kelayakan produk yang dikembangkan sebagai dasar untuk melakukan perbaikan terhadap pengembangan desain media pembelajaran matematika berbasis aplikasi prezi pada materi fungsi . Hasil validasi yang berupa data kuantitatif selanjutnya dikonversi ke dalam bentuk data kualitatif dengan konversi skala likert.

Validasi yang pertama dilakukan ialah validasi media pembelajaran yang telah selesai dibuat kemudian divalidasi oleh ahli media. Berdasarkan hasil validasi ahli media tahap 1, maka diperoleh skor sebesar 27 dengan kriteria "Sedang/Cukup", sehingga dapat ditarik kesimpulan bahwa multimedia yang disajikan masih perlu direvisi, dan belum siap untuk di uji cobakan. Kemudian dilakukan lagi validasi ahli media tahap 2 sehingga menghasilkan skor sebesar 33 dengan kriteria "Baik/Menarik". Disini peneliti melakukan validasi pada ahli media sebanyak tiga tahap untuk memperoleh kriteria "Sangat Baik/Sangat Menarik". Berikut hasil validasi ahli media tahap 3 dapat dilihat pada Tabel 2, sebagai berikut : 
Desimal, 2 (1), 2019 - 27

Rohiman, Bambang Sri Anggoro

Tabel 2. Hasil Validasi Ahli Media Tahap 3

\begin{tabular}{|c|c|c|c|}
\hline No & Aspek & Kriteria & Skor \\
\hline \multirow[t]{4}{*}{1} & Efisiensi Media & $\begin{array}{l}\text { 1. Kemudahan dalam penggunaan } \\
\text { aplikasi prezi }\end{array}$ & 3 \\
\hline & & $\begin{array}{l}\text { 2. Kemudahan dalam penggunaan menu } \\
\text { aplikasi prezi }\end{array}$ & 3 \\
\hline & & $\begin{array}{l}\text { 3. Kemudahan berinteraksi dengan } \\
\text { aplikasi prezi }\end{array}$ & 4 \\
\hline & & $\begin{array}{l}\text { 4. Kemudahan masuk dan keluar aplikasi } \\
\text { prezi }\end{array}$ & 4 \\
\hline \multirow[t]{2}{*}{2} & Fungsi tombol & $\begin{array}{l}\text { 1. Kemudahan memahami struktur } \\
\text { aplikasi prezi }\end{array}$ & 4 \\
\hline & & 2. Ketepatan reaksi button(tombol) & 3 \\
\hline \multirow[t]{7}{*}{3} & Grafis & 1. Tata letak teks dan gambar & 4 \\
\hline & & 2. Kesesuaian pemilihan background & 4 \\
\hline & & $\begin{array}{l}\text { 3. Kesesuain pemilihan ukuran dan jenis } \\
\text { huruf }\end{array}$ & 4 \\
\hline & & 4. Kesesuaian warna & 4 \\
\hline & & 5. Kemenarikan sajian gambar frime & 4 \\
\hline & & $\begin{array}{l}\text { 6. Kesesuain pemilihan gambar frime } \\
\text { dengan materi }\end{array}$ & 4 \\
\hline & Jumlah & & 45 \\
\hline
\end{tabular}

Berdasarkan Tabel 2, hasil validasi ahli media tahap 3 diperoleh skor sebesar 45 dengan kriteria "Sangat Baik/Sangat Menarik" artinya validator sudah menyatakan bahwa media layak untuk diuji cobakan. Validasi yang kedua adalah validasi ahli materi. Setelah ahli materi melihat dan mengoperasikan media pembelajaran yang telah dirancang, selanjutnya ahli materi menilai kesesuaian materi dengan gambar dan video yang ditampilkan dalam media dan kesesuaian materi yang ditampilkan dengan kurikulum.

Berdasarkan hasil validasi ahli materi tahap 1, maka diperoleh skor sebesar 27 dengan kriteria "Sedang/Cukup". Validator menyatakan bahwa media tersebut layak diuji cobakan ke lapangan dengan revisi/perbaikan. Setelah dilakukan revisi, maka dilakukan lagi validasi ahli materi tahap 2. Berikut hasil validasi ahli materi tahap 2 dapat dilihat pada Tabel 3, sebagai berikut: 
Desimal, 2 (1), 2019 - 28

Rohiman, Bambang Sri Anggoro

Tabel 3. Hasil Validasi Ahli Materi Tahap 2

\begin{tabular}{|c|c|c|c|}
\hline No & Aspek & Kriteria & Skor \\
\hline \multirow[t]{4}{*}{1} & \multirow[t]{5}{*}{ Materi } & $\begin{array}{l}\text { 1. Kesesuaian materi dengan standar } \\
\text { kompetensi }\end{array}$ & 3 \\
\hline & & $\begin{array}{l}\text { 2. Kesesuaian materi dengan kompetensi } \\
\text { dasar }\end{array}$ & 3 \\
\hline & & $\begin{array}{l}\text { 3. Kesesuaian materi dengan tujuan } \\
\text { pembelajaran }\end{array}$ & 3 \\
\hline & & $\begin{array}{l}\text { 4. Uraian isi materi } \\
\text { 5. Kejelasan contoh yang disertakan }\end{array}$ & $\begin{array}{l}3 \\
3\end{array}$ \\
\hline \multirow[t]{3}{*}{2} & & 1. Kejelasan bahasa yang digunakan & 3 \\
\hline & Bahasan & $\begin{array}{l}\text { 2. Kesesuaian bahasa dengan sasaran } \\
\text { pengguna( peserta didik SMP kelas } \\
\text { VIII) }\end{array}$ & 3 \\
\hline & & 3. Penulisan materi mudah dipahami. & 4 \\
\hline \multirow[t]{3}{*}{3} & Evaluasi & $\begin{array}{l}\text { 1. Keseimbangan dengan evaluasi dengan } \\
\text { mateti }\end{array}$ & 3 \\
\hline & & $\begin{array}{l}\text { 2. Kesesuaian evaluasi dengan } \\
\text { kompetensi }\end{array}$ & 3 \\
\hline & Jumlah & & 31 \\
\hline
\end{tabular}

Berdasarkan Tabel 3, hasil validasi ahli materi tahap 2 diperoleh skor sebesar 31 dengan kriteria "Baik/Menarik" artinya validator sudah menyatakan bahwa media layak untuk diuji cobakan. Setelah dilakukan validasi oleh ahli materi dan ahli media, selanjutnya dilakukan uji coba terhadap peserta didik kelas VIII yaitu sebanyak 33 orang. Instrumen yang digunakan berupa angket terbuka dengan menggunakan skala Likert. Angket respon peserta didik diberikan kepada 33 orang peserta didik.

Berdasarkan hasil persentasi skor secara keseluruhan respon peserta didik dengan nilai $82,2 \%$ dan melihat data tabel skala penilaian kualifikasi produk, maka produk yang dikembangkan oleh pengembang dapat dikategorikan "Sangat Menarik". Berpedoman pada hal tersebut, skor maksimal adalah 1558 sedangkan jumlah skor yang diperoleh 1308. Maka persentasenya adalah:

$$
x_{i}=\frac{1308}{1558} \times 100 \%=83,9 \%
$$

Jika dilihat berdasarkan hasil persentasi skor secara keseluruhan respon peserta didik dengan nilai 83,9\% dan melihat data tabel skala penilaian kualifikasi produk, maka produk yang dikembangkan oleh pengembang dapat dikategorikan sangat menarik.

Berdasarkan penelitian terdahulu, telah dilakukan beberapa penelitian yang mengembangkan media pembelajaran matematika berbasis prezi, beberapa diantaranya Mohammad Yusuf Rodhi mengembangkan media pembelajaran matematika berbasis prezi untuk meningkatkan keterampilan berpikir kritis peserta didik. Dari hasil penelitiannya dapat disimpulkan bahwa telah dihasilkan media pembelajaran berbasis prezi pada materi kalor yang memenuhi kriteria kelayakan baik dari segi materi maupun dari segi format tampilan media, dengan kategori sangat layak. Ada penelitian dari Yunanik Antika, Yunanik menyimpulkan hasil penelitiannya bahwa hasil validasi oleh validator dinyatakan valid dengan presentase $85 \%$, respon peserta didik sangat baik dengan presentase $87.46 \%$ serta hasil belajar peserta didik mengalami peningkatan dengan rata-rata sebesar 0.79 dengan menggunakan media pembelajaran berbasis Prezi pada mata 
pelajaran Rangkaian Elektronika (Antika \& Suprianto, 2016).

Amalia Nurul Hidayati juga mengungkapkan bahwa media pembelajaran presentasi berbasis program aplikasi prezi materi bipolar junction transistor (BJT) sebagai penguat dan piranti saklar layak digunakan sebagai pendamping guru dalam mengajar (Hidayati \& Santoso, 2016), Surani juga mengungkapkan bahwa desain media pembelajaran prezi pada mata pelajaran membuat pola dianggap layak untuk dijadikan desain media pembelajaran (Surani \& Ampera, 2017) dan Mukhammad Karim juga menyimpulkan bahwa media pembelajaran berbasis Prezi sangat valid untuk digunakan dan menarik bagi peserta didik (Karim \& Agung, 2018). Dalam penelitian ini, pengembangan media pembelajaran matematika berbasis prezi untuk meningkatkan minat belajar peserta didik pada pokok bahasan fungsi, di dapatkan hasil bahwa media pembelajaran matematika berbasis prezi pada pokok bahasan fungsi memiliki kriteria sangat baik dari segi media, materi dan respon peserta didik dengan menggunakan skala Likert serta serta minat belajar peserta didik mengalami peningkatan.

\section{KESIMPULAN DAN SARAN}

Berdasarkan hasil penelitian dan pengembangan yang telah dilakukan, maka dapat disimpulkan bahwa pengembangan ini menggunakan beberapa tahapan yang dikutip dari model Munir (Analisis, Desain, Pengembangan, dan Uji Coba) yaitu tahap pengembangan meliputi proses validasi, proses validasi yang dilakukan oleh ahli materi dan ahli media. Tahap uji coba meliputi tahap uji coba terhadap peserta didik berjumlah 33 orang peserta didik agar menghasilkan respon yang sangat menarik tehadap produk yang dihasilkan, tahap uji coba dilakukan sebanyak satu kali yaitu uji coba kelompok kecil di SMP/MTs.

Berdasarkan hasil rata-rata dari penilaian ahli materi sebesar 84\% dengan kategori "Baik", penilaian ahli media diperoleh rata-rata sebesar $78 \%$ dengan kategori "Sangat Baik" dan penilaian uji coba peserta didik diperoleh rata-rata sebesar $83,9 \%$ yang menunjukkan pada kategori "Sangat Baik", maka secara keseluruhan penilaian dari ahli materi, ahli media dan peserta didik terhadap pengembangan media pembelajaran matematika berbasis prezi dengan hasil rata-rata masuk pada kategori "Sangat Baik" untuk dijadikan sebagai media pembelajaran matematika.

Berdasarkan kesimpulan dan refleksi tiap siklus, penggunaan media pembelajaran aplikasi prezi (zooming presentation) sebagai usaha untuk meningkatkan minat belajar maka peneliti memberi saran kepada peneliti untuk tidak berhenti sampai disini, agar selalu mencari ilmu dimanapun berada dan mengamalkan ilmu yang telah didapat sehingga ilmu tidak hilang begitu saja. Kepada peneliti berikutnya untuk lebih bersungguh-sungguh dalam menulis karya ilmiah dan melakukan penelitian agar apa yang didapat oleh peneliti dan peserta didik lebih banyak, sehingga dapat berguna.

\section{DAFTAR PUSTAKA}

Ali, M. (2009). Pengembangan Media Pembelajaran Interaktif Mata Kuliah Medan Elektromagnetik. Jurnal Edukasi@Elektro,5(1),11-18.

Amir, M. F., \& Wardana, M. D. K. (2017). Pengembangan Domino Pecahan Berbasis Open Ended untuk Meningkatkan Kemampuan Berpikir Kreatif Siswa SD. Aksioma, 6(2), 178188.

Andreanto, E., \& Suprianto, B. (2018). Pengembangan Media Pembelajaran 
Trainer Microcontroller Berbasis Arduino Uno dengan Menerapkan Aplikasi Sistem Radar dan RFID pada Mata Pelajaran Perekayasaan Sistem Kontrol di SMK Negeri 2 Bangkalan. Jurnal Pendidikan Teknik Elektro, 7(2), 183-192.

Antika, Y., \& Suprianto, B. (2016). Pengembangan Media Pembelajaran Berbasis Prezi sebagai Upaya Meningkatkan Hasil Belajar Siswa Kompetensi Dasar Aplikasi Rangkaian Op Amp Mata Pelajaran Rangkaian Elektronika di SMK Negeri 2 Bojonegoro. Jurnal Pendidikan Teknik Elektro, 5(2), 493497.

Argarini, D. F., \& Sulistyorini, Y. (2018). Pengembangan Media Pembelajaran Berbasis Prezi pada Matakuliah Analisis Vektor. KALAMATIKA Jurnal Pendidikan Matematika, 3(2), 209222.

Asfuriyah, S., \& Nuswowati, M. (2015). Pengembangan Majalah Sains Berbasis Contextual Learning pada Tema Pemanasan Global untuk Meningkatkan Minat Belajar Siswa. Unnes Science Education Journal, 4(1), 739-746.

Damayanti, D. S., Ngazizah, N., \& Setyadi K, E. (2013). Pengembangan Lembar Kerja Siswa ( LKS ) dengan Pendekatan Inkuiri Terbimbing untuk Mengoptimalkan Kemampuan Berpikir Kritis Peserta Didik pada Materi Listrik Dinamis SMA Negeri 3 Purworejo Kelas X Tahun Pelajaran 2012 / 2013. Radiasi, 3(1), 58-62.

Hartini, S., Misbah, Dewantara, D., Oktovian, R. A., \& Aisyah, N. (2017). Developing Learning Media using Online Prezi into Materials about Optical Equipments. Jurnal Pendidikan IPA Indonesia, 6(2), 313317.

https://doi.org/10.15294/jpii.v6i2.1 0102

Hidayati, A. N., \& Santoso, A. B. (2016).
Pengembangan Media Pembelajaran Presentasi Berbasis Program Aplikasi Prezi pada Standar Kompetensi Dasar Elektronika di SMK Negeri 3 Surabaya. Jurnal Pendidikan Teknik Elektro, 5(1), 659665.

I, M. S., \& Mahayukti, G. A. (2013). Pengembangan E-Modul Berorientasi Pemecahan Masalah untuk Meningkatkan Keterampilan Berfikir Kritis Mahasiswa. Jurnal Pendidikan Indonesia, 2(2), 264-275.

Jannah, M., Sugianto, \& Sarwi. (2012). Pengembangan Perangkat Pembelajaran Berorientasi Nilai Karakter Melalui Inkuiri Terbimbing Materi Cahaya pada Siswa Kelas VIII Sekolah Menengah Pertama. Journal of Innovative Science Education, 1(1), $1-7$.

Karim, M., \& Agung, Y. A. (2018). Pengembangan Media Pembelajaran Berbasis Prezi pada Mata Pelajaran Penerapan Rangkaian Elektronika Kelas XI di SMK Negeri 1 Sidoarjo. Jurnal Pendidikan Teknik Elektro, 7(2), 143-149.

Khoiri, N., Hindarto, N., \& Sulhadi. (2011). Pengembangan Perangkat Pembelajaran Fisika Berbasis Life Skill untuk Meningkatkan Minat Kewirausahaan Siswa. Jurnal Pendidikan Fisika Indonesia, 7(2), 84-88.

Megawati, C. (2014). Pengembangan Media Pembelajaran Bipa Tingkat Menengah Melalui E-Book Interaktif di Programincountry Universitas Negeri Malang Tahun 2014. NOSI, 2(1), 62-70.

Munir. (2012). Multimedia Konsep dan Aplikasi dalam Pendidikan. Bandung: Alfabeta.

Nisa', C., \& Agung, Y. A. (2014). Pengembangan Media Pembelajaran Berbasis ICT Menggunakan Multisim10 Simulations pada Mata Pelajaran Teknik Elektronika Dasar 
di SMK Negeri 7 Surabaya. Jurnal Pendidikan Teknik Elektro, 3(2), 311317.

Purwanti, B. (2015). Pengembangan Media Video Pembelajaran Matematika dengan Model Assure. Jurnal Kebijakan Dan Pengembangan Pendidikan, 3(1), 42-47.

Restika, R. R., Ibrahim, M., \& Kuswanti, N. (2016). Validitas Media Prezi the Zooming Presentation pada Materi Sistem Pencernaan Makanan Manusia. Berkala Ilmiah Pendidikan Biologi, 5(3), 213-219.

Retnawati, Y., Rasiman, \& Handayani, D. E. (2018). Keefektifan Model Problem Solving dengan Media Prezi Terhadap Kemampuan Memecahkan Masalah Matematika Siswa Kelas IV SD. Jurnal Sekolah (JS), 2(4), 365372.

Rodhi, M. Y., \& Wasis. (2014). Pengembangan Media Pembelajara Berbasis Prezi untuk meningkatkan keterampilan Berpikir Kritis Pada Materi Kalor. Jurnal Inovasi Pendidikan Fisika (JIPF), 3(2), 137142.

Rusyfian, Z. (2016). Prezi Solusi Presentasi Masa Kini untuk Pelajar, Mahasiswa, dan Pebisnis (Cet ke-1). Bandung: Informatika Bandung.

Safitri, M., Hartono, Y., \& Somakim. (2013). Pengembangan Media Pembelajaran Matematika Pokok Bahasan Segitiga Menggunakan Macromedia Flash untuk Siswa Kelas VII SMP. Jurnal Pendidikan, 14(2), 62-72.

Safitri, M. R., Budiharti, R., \& Ekawati, E. Y. (2014). Pengembangan Media Pembelajaran IPA Terpadu Interaktif dalam Bentuk Moodle untuk Siswa SMP pada Tema Hujan Asam. Jurnal Pendidikan Fisika, 2(1), 1-5.

Setiawan, K., \& Joko. (2016). Pengembangan dan Penelitian Media Pembelajaran Interaktif Dilengkapi Software Prezi untuk Meningkatkan
Hasil Belajar Mata Pelajaran Instalasi Penerangan Listrik Kelas XI TIPTL SMK Negeri 1 Nganjuk. Jurnal Pendidikan Teknik Elektro, 5(1), 4552.

Setyono, Y. A., Sukarmini, \& Wahyuningsih, D. (2013). Pengembangan Media Pembelajaran Fisika Berupa Buletin dalam Bentuk Buku Saku untuk Pembelajaran Fisika Kelas VIII Materi Gaya Ditinjau dari Minat Baca Siswa. Jurnal Pendidikan Fisika, 1(1), 118-126.

Somayasa, W., Natajaya, N., \& Candiasa, M. (2013). Pengembangan Modul Matematika Realistik Disertai Asesmen Otentik untuk Meningkatkan Hasil Belajar Matematika Peserta Didik Kelas X di SMK Negeri 3 Singaraja. E-Journal Program Pascasarjana Universitas Pendidikan Ganesha, 3, 1-12.

Sugiyono. (2013). Metode Penelitian Pendidikan. Bandung: Alfabeta.

Sujarwo, A., \& Kholis, N. (2016). Pengembangan Media Pembelajaran Menggunakan Prezi pada Mata Pelajaran Sistem Komputer di SMK Negeri 3 Buduran. Jurnal Pendidikan Teknik Elektro, 5(3), 897-901.

Suprapti, E. (2016). Pengembangan Perangkat Pembelajaran Matematika Model Kooperatif Tipe STAD dengan Media Powerpoint Ispring pada Materi Jajargenjang, Layang-Layang, dan Trapesium di Kelas VII SMP. Journal of Mathematics Education, Science and Technology, 1(1), 57-68.

Surani, \& Ampera, D. (2017). Pengembangan Media Pembelajaran Prezi pada Mata Pelajaran Membuat Pola di SMK Awal Karya Pembangunan Galang. Jurnal Pendidikan Teknologi Dan Kejuruan, 19(1), 13-18.

Sutopo, A. H. (2012). Teknologi Informasi dan Komunikasi dalam Pendidikan. Yogyakarta: Graha Ilmu.

Utari, Y. P., Kurniawan, E. S., \& 
Desimal, 2 (1), 2019 - 32

Rohiman, Bambang Sri Anggoro

Fatmaryanti, S. D. (2014). Pengembangan Media Pembelajaran Fisika Online Prezi dalam Pokok Bahasan Alat Optik pada Siswa Kelas $X$ IPA SMA Negeri 3 Purworejo Tahun Pelajaran 2013/2014. Radiasi, 5(2), 45-49.

Wahyudi, B. S., Hariyadi, S., \& Hariani, S. A. (2014). Pengembangan Bahan Ajar Berbasis Model Problem Based Learning pada Pokok Bahasan Pencemaran Lingkungan untuk Meningkatkan Hasil Belajar Siswa Kelas X SMA Negeri Grujugan Bondowoso. Pancaran, 3(3), 83-92.

Wahyudin, Sutikno, \& Isa, A. (2010). Keefektifan Berbantuan Pembelajaran Menggunakan Metode Inkuiri
Terbimbing untuk Meningkatkan Minat dan Pemahaman Siswa. Jurnal Pendidikan Fisika Indonesia 6, 6(1), 58-62.

Widiyatmoko, A. (2013). Pengembangan Perangkat Pembelajaran IPA Terpadu Berkarakter Menggunakan Pendekatan Humanistik Berbantu Alat Peraga Murah. Jurnal Pendidikan IPA Indonesia, 2(1), 76-82.

Yulianti, Buchori, A., \& Murtianto, Y. H. (2017). Pengembangan Media Presentasi Visual dengan Pendekatan Kontekstual dalam Pembelajaran Matematika di SMP. Journal of Mathematics Education, Science and Technology, 2(2), 231242. 